service would be adopted. He did not suggest that no development of these clinics should take place apart from the local educational authority, but rather that there should be a close co-operation. Thus the active interest of the local authority should be won for a clinic, even though not directly initiated, financed, or controlled by it. Dr. Crowley paid high tribute to the child guidance work already existing in Great Britain, mentioning clinics at various hospitals and institutions, both medical and educational. He referred particularly to the outstanding work of Professor Cyril Burt as psychologist to the London County Council, and to that of Dr. Robert Hughes, school medical officer of Stoke-on-Trent. We have previously referred to the inauguration of the Child Guidance Council, which proposes to establish next year a clinic in London through the generosity of the Commonwealth Fund of New York. The clinic has secured the full co-operation of the London County Council, which will be represented on the managing body. Dr. Crowley hoped that effective clinics on a less ambitious scale would be established before long to serve the needs of smaller institutions. These would doubtless be the outcome, as a rule, of voluntary initiative in their early stages, and later on the time would come to consider how this work could best be related to other already existing activities.

\section{THE DEATH PENALTY.}

There is a National Council for the Abolition of the Death Penalty, which has Lord Buckmaster as its president. The council has determined upon a forward movement for the attainment of its object, and in a letter to the Times Lord Buckmaster sets out the propositions: (1) that " recent events-notably the result of the Slater appeal and the Home Secretary's eleventh-hour reprieve, because of an ' element of doubt,' of the three men convicted of the Brighton murder-have raised the capital punishment issue in an acute form"; (2) that "its abolition by Parliament without the assurance of public support would be premature"; and (3) that "there remains but one constitutional way in which public opinion can find expression" on this subject-namely, "a national petition to Parliament." $\mathrm{He}$ appeals to "all those whose considered opinion it is that the death penalty could be dispensed with" to sign such a petition. With the form of petition his council has issued a memorandum giving eleven reasons in support of it. The matter is a serious one, and Lord Buckmaster's support is very weighty. It may nevertheless be doubted whether there really exists any strong public opinion upon this question which requires expression; whether recent events, important as they are, can be said to have made the issue an acute one; and whether any petition to Parliament can really be taken to indicate either the volume or the intensity of such public opinion as there is. Individual reasons for signing a petition are numerous, and the signature can by no means usually be regarded as the result of a " considered opinion." The public mind on this matter is probably in a condition of indifference or uncertainty. It seems unlikely that if any Government proposed to abolish the death penalty there would be any great volume of opposition to such proposal. On the other hand, a great deal of propaganda is necessary if Governmental action is to be undertaken only as the result of public pressure. The petition and accompanying memorandum now before the public may be regarded as useful propaganda, though of the eleven stated reasons against capital punishment some are much less weighty than others. A further excellent piece of pròpaganda recently published is a little book by Charles Duff entitled $A$ Handbook on Hanging. ${ }^{1}$ Its title-page, in the old style, describes it as A Handbook on Hanging. By Charles Duff. London: Grant Richards
and P. Sainsbury, The Caymo Press, Ltd. 1928. (Fcap. 8vo, pp. 127.)
" a short introduction to the fine art of execution containing much useful information ... as well as data and wrinkles for hangmen . . . to which is added a Hangman's Ready Reckoner." It is a remarkably effective sustained piece of irony, not unworthy to be mentioned with those masterpieces in the same line, Fielding's History of Mr. Jonathan Wild the Great and De Quincey's essay on Murder Considered as one of the Fine Arts, and can be strongly recommended either to those who do not object to gather their facts and arguments in a somewhat gruesome medium or to those who can enjoy an ironic effort purely for its literary merits.

THrs year's Norman Lockyer Lecture, arranged by the British Science Guild, will be given by Professor J. Arthur Thomson on the aftermoon of Wednesday, November 28th, in the Goldsmiths' Hall, London. The subject will be "The culture value of natural history."

\section{USE OF CLOVER'S INHALER IN TONSILLECTOMY AND REMOVAL OF ADENOIDS.}

\author{
BY
}

Sir CHARTERS J. SYMONDS, K.B.E., C.B., F.R.C.S., CONSULTING SURGEON TO GUY'S HOSPITAL.

Is response to personal requests and an invitation from the Editor of the Journal, I give a brief description of the employment of Clover's inhaler for inducing anaesthesia in the removal of tonsils and adenoids. In doing so let me first say that my communication (September 8th, p. 465) was in no way intended to suggest that ether was not widely used, for the open method is now generally employed, though there are advocates for chloroform and ethyl chloride; nor do I presume to instruct the anaesthetists, to whom all methods must bo familiar.

First one must gain the confidence of the child and eliminate fear as far as possible. Let the child blow up the bag 'as it would a balloon, then adjust the face-piece, and ask the child to blow it up, removing the face-piece two or three times so as to get the bag filled. The second and important stage is to allow rebreathing of the air until the face becomes dusky, by which time the child will be rendered so far unconscious as not to detect the admission of ether, which is now gradually admitted. If the child struggles after a few inhalations of ether, this is due to the $\mathrm{CO}_{2}$, and will bo checked by admitting air, not by increasing the ether. If there be no struggling, remove the face-piece when the cyanosis increases, and allow three breaths of air, when the immediate return of colour is evidence that it is due to the $\mathrm{CO}_{2}$ and not ether.

By this time the child will be so far insensible that the ether can now be admitted without a check until full anaesthesia is obtained. It is necessary to remove the face-piece and admit free air from time to time, foi in this stage there should be no cyanosis. Air must also be admitted in this stage should there be any struggling.

Wheir the conjunctiva has become insensitive and has remained so for a minute or longer, the face-piece is removed, and if after three or four full breaths it remains insensitive the anaesthesia should last for four minutes or more. Should the child move or the conjunctiva become sensitive more ether should be given. It requires some practice and judgement to know when to admit the ether, and how long to continue before removing the face-piece and admitting air.

It will be noticed that rebreathed air produces the first stage of unconsciousness, and there being no objectionable odour the fear of suffocation is almost eliminated. One great advantage over open ether is the absence of mucus, with the associated coughing and congestion. Many children cannot submit without fear and struggling, and must bo controlled, but it is remarkable how quickly they settle down under the rebreathed air.

The same procedure answers in adults, omitting, of course, the preliminary play. 